Research

Open Access

\title{
Continuous terlipressin versus vasopressin infusion in septic shock (TERLIVAP): a randomized, controlled pilot study
}

\author{
Andrea Morelli ${ }^{1}$, Christian Ertmer ${ }^{2}$, Sebastian Rehberg ${ }^{2}$, Matthias Lange ${ }^{2}$, Alessandra Orecchioni ${ }^{1}$, \\ Valeria Cecchini ${ }^{1}$, Alessandra Bachetoni ${ }^{3}$, Mariadomenica D'Alessandro ${ }^{3}$, Hugo Van Aken², \\ Paolo Pietropaoli ${ }^{1}$ and Martin Westphal ${ }^{2}$
}

\begin{abstract}
1Department of Anesthesiology and Intensive Care, University of Rome, "La Sapienza", Viale del Policlinico 155, Rome 00161, Italy 2Laboratory of Clinical Pathology, Department of Surgery, University of Rome, "La Sapienza", Viale del Policlinico 155, Rome 00161, Italy

${ }^{3}$ Department of Anesthesiology and Intensive Care, University Hospital of Muenster, Albert-Schweitzer-Strasse 33, Muenster 48149, Germany
\end{abstract}

Corresponding author: Andrea Morelli, andrea.morelli@uniroma1.it

Received: 3 Jun 2009 Revisions requested: 30 Jun 2009 Revisions received: 13 Jul 2009 Accepted: 10 Aug 2009 Published: 10 Aug 2009

Critical Care 2009, 13:R130 (doi:10.1186/cc7990)

This article is online at: http://ccforum.com/content/13/4/R130

(c) 2009 Morelli et al.; licensee BioMed Central Ltd.

This is an open access article distributed under the terms of the Creative Commons Attribution License (http://creativecommons.org/licenses/by/2.0), which permits unrestricted use, distribution, and reproduction in any medium, provided the original work is properly cited.

\begin{abstract}
Introduction Recent clinical data suggest that early administration of vasopressin analogues may be advantageous compared to a last resort therapy. However, it is still unknown whether vasopressin and terlipressin are equally effective for hemodynamic support in septic shock. The aim of the present prospective, randomized, controlled pilot trial study was, therefore, to compare the impact of continuous infusions of either vasopressin or terlipressin, when given as first-line therapy in septic shock patients, on open-label norepinephrine requirements.
\end{abstract}

Methods We enrolled septic shock patients $(n=45)$ with a mean arterial pressure below $65 \mathrm{mmHg}$ despite adequate volume resuscitation. Patients were randomized to receive continuous infusions of either terlipressin $\left(1.3 \mu \mathrm{g} \cdot \mathrm{kg}^{-1} \cdot \mathrm{h}^{-1}\right)$, vasopressin $\left(.03 \mathrm{U} \cdot \mathrm{min}^{-1}\right)$ or norepinephrine $\left(15 \mu \mathrm{g} \cdot \mathrm{min}^{-1} ; \mathrm{n}=15\right.$ per group). In all groups, open-label norepinephrine was added to achieve a mean arterial pressure between 65 and $75 \mathrm{mmHg}$, if necessary. Data from right heart and thermo-dye dilution catheterization, gastric tonometry, as well as laboratory variables of organ function were obtained at baseline, 12, 24, 36 and 48 hours after randomization. Differences within and between groups were analyzed using a two-way ANOVA for repeated measurements with group and time as factors. Timeindependent variables were compared with one-way ANOVA.

Results There were no differences among groups in terms of systemic and regional hemodynamics. Compared with infusion of .03 $\mathrm{U}$ of vasopressin or $15 \mu \mathrm{g} \cdot \mathrm{min}^{-1}$ of norepinephrine, 1.3 $\mu \mathrm{g} \cdot \mathrm{kg}^{-1} \cdot \mathrm{h}^{-1}$ of terlipressin allowed a marked reduction in catecholamine requirements $(0.8 \pm 1.3$ and $1.2 \pm 1.4$ vs. $0.2 \pm$ $0.4 \mu \mathrm{g} \cdot \mathrm{kg}^{-1} \cdot \mathrm{min}^{-1}$ at 48 hours; each $\left.P<0.05\right)$ and was associated with less rebound hypotension $(P<0.05)$. At the end of the 48-hour intervention period, bilirubin concentrations were higher in the vasopressin and norepinephrine groups as compared with the terlipressin group $(2.3 \pm 2.8$ and $2.8 \pm 2.5$ vs. $0.9 \pm 0.3 \mathrm{mg} \cdot \mathrm{dL}^{-1}$; each $\left.P<0.05\right)$. A time-dependent decrease in platelet count was only observed in the terlipressin group $(P<0.00148$ hours vs. BL).

Conclusions The present study provides evidence that continuous infusion of low-dose terlipressin - when given as first-line vasopressor agent in septic shock - is effective in reversing sepsis-induced arterial hypotension and in reducing norepinephrine requirements.

Trial registration ClinicalTrial.gov NCT00481572.

ANOVA: analysis of variance; AVP: arginine vasopressin; BILD: direct bilirubin; BILT: total bilirubin; CBI: blood clearance of indocyanine green related to body surface area; $\mathrm{Cl}$ : cardiac index; $\mathrm{DO}_{2}$ I: systemic oxygen delivery index; $\mathrm{FiO}_{2}$ : fraction of inspired oxygen; $\mathrm{HR}$ : heart rate; ICU: intensive care unit; IL: interleukin; LVSWI: left ventricular stroke work index; MAP: mean arterial pressure; MPAP: mean pulmonary arterial pressure; NE: norepinephrine; $\mathrm{O}_{2}$-ER: oxygen extraction rate; $\mathrm{PaO}_{2}$ : partial pressure of arterial oxygen; PAOP: pulmonary arterial occlusion pressure; PDR: plasma disappearance rate of indocyanine green; PVRI: pulmonary vascular resistance index; RAP: right atrial pressure; RVSWI: right ventricular stroke work index; SAPS II: Simplified Acute Physiology Score II; SD: standard deviation; $\mathrm{SvO}_{2}$ : mixed-venous oxygen saturation; SVRI: systemic vascular resistance index; TNF: tumor necrosis factor; TP: terlipressin; VASST: Vasopressin and Septic Shock Trial; $\mathrm{VO}_{2} \mathrm{I}$ : systemic oxygen consumption index. 


\section{Introduction}

In the past few years, it has become evident that the efficacy of hemodynamic optimization by fluids and vasopressor agents critically depends on the urgency of therapy [1-4]. The recent Vasopressin and Septic Shock Trial (VASST) [5] revealed that survival was only improved in the subgroup of patients receiving vasopressin (AVP) in the less severe state of disease, as indicated by low doses of norepinephrine (NE) infusion (i.e. $\leq 15 \mu \mathrm{g} / \mathrm{min}$ ) prior to randomization. In some European countries, however, AVP is not available, and thus terlipressin (TP), a synthetic, long-acting vasopressin analogue, is commonly considered as last resort therapy in the late phase of septic shock, when high dosages of catecholamines fail to counteract sepsis-related arterial hypotension [6-9]. Due to its long effective half-life of four to six hours, TP is commonly administered as high-dose bolus infusion (about $1 \mathrm{mg}$ every four to six hours). The potential problem, however, is that TP bolus infusion may contribute to excessive vasoconstriction and a reflectory decrease in cardiac output with a proportional depression in oxygen delivery [10]. This may be especially problematic in a condition of increased oxygen demand, such as early sepsis $[1,3]$. Notably, preliminary experimental and clinical reports have shown that TP may also be administered as low-dose continuous infusion, thereby mitigating, or even preventing such adverse events [10-14]. The optimal time of therapy, however, remains to be determined.

Preliminary results from a comparative experimental study of AVP versus TP in ovine septic shock suggested that continuous infusion of TP may improve survival and increase mesenteric perfusion as compared with AVP [15]. In addition, it has been reported that a highly selective $V_{1}$ agonist (FE 202158) markedly reduced vascular leakage and mortality in experimental sepsis as compared with AVP $[16,17]$. Nevertheless, a direct comparison between a continuous infusion of a relatively selective $V_{1}$ agonist, such as TP, and AVP on catecholamine requirements in human septic shock has not yet been performed. We hypothesized that the relatively selective $\mathrm{V}_{1}$ receptor agonist TP is likewise advantageous when compared with AVP in human septic shock.

Therefore, we conducted a randomized controlled clinical pilot study to compare the effects of first-line institution of continuous, fixed doses of TP and AVP infusion on open-label NE requirements in patients with septic shock. In addition, we aimed to investigate the effects of both vasopressor agents on systemic and regional hemodynamics as well as organ function.

\section{Materials and methods Patients}

After approval by the Local Institutional Ethics Committee, the study was performed in an 18-bed multidisciplinary intensive care unit (ICU) of the Department of Anesthesiology and Intensive Care of the University of Rome 'La Sapienza'. Due to the protocol design, informed consent was obtained from the patients' next of kin at the time of ICU admission. Enrolment of patients started in January 2007 and ended in January 2008. We enrolled patients who fulfilled the criteria of septic shock [3] presenting with a mean arterial pressure (MAP) below 65 $\mathrm{mmHg}$ despite appropriate volume resuscitation (pulmonary arterial occlusion pressure (PAOP) $=12$ to $18 \mathrm{mmHg}$ and central venous pressure $=8$ to $12 \mathrm{mmHg}$ ) [3] during the ICU stay.

Exclusion criteria were age less than 18 years, catecholamine therapy prior to randomization, pronounced cardiac dysfunction (i.e. cardiac index $\leq 2.2 \mathrm{~L} / \mathrm{min} / \mathrm{m}$ in the presence of PAOP $>18 \mathrm{mmHg}$ ), chronic renal failure, severe liver dysfunction (Child-Turcotte-Pugh grade C), significant valvular heart disease, present coronary artery disease, pregnancy, and present or suspected acute mesenteric ischemia or vasospastic diathesis (e.g. Raynaud's syndrome or related diseases).

All patients were sedated with sufentanil and midazolam and received mechanical ventilation using a volume-controlled mode.

\section{Measurements}

Systemic hemodynamic monitoring of the patients included a pulmonary artery catheter (7.5-F, Edwards Lifesciences, Irvine, CA, USA) and a radial artery catheter. MAP, right atrial pressure (RAP), mean pulmonary arterial pressure (MPAP), and PAOP were measured at end-expiration. Heart rate $(H R)$ was analyzed from a continuous recording of electrocardiogram with ST segments monitored. Cardiac index $(\mathrm{Cl})$ was measured using the continuous thermodilution technique (Vigilance $\|{ }^{\circledR}$, Edwards Lifesciences, Irvine, CA, USA). Arterial and mixed-venous blood samples were taken to determine oxygen tensions and saturations, as well as carbon dioxide tensions, standard bicarbonate and base excess. Mixed-venous oxygen saturation $\left(\mathrm{SvO}_{2}\right)$ was measured discontinuously by intermittent mixed-venous blood gas analyses. Systemic vascular resistance index (SVRI), pulmonary vascular resistance index (PVRI), left and right ventricular stroke work indices (LVSWI, RVSWI), systemic oxygen delivery index $\left(\mathrm{DO}_{2} \mathrm{l}\right)$, oxygen consumption index $\left(\mathrm{VO}_{2} \mathrm{l}\right)$, and oxygen extraction ratio $\left(\mathrm{O}_{2}-\mathrm{ER}\right)$ were calculated using standard formulae.

Regional hemodynamic monitoring was performed using a 4-F oximetry thermo-dye dilution catheter (PV2024L, Pulsion Medical System AG, Munich, Germany) inserted into the femoral artery for the measurement of plasma disappearance rate (PDR) and blood clearance of indocyanine green related to body surface area (CBI). PDR and $\mathrm{CBI}$ were determined with the Cold Z-021 system (Pulsion Medical System AG, Munich, Germany) using an established protocol $[18,19]$. In addition, an air-tonometer (Tonocap, Datex-Ohmeda, Helsinki, Finland) was inserted via the naso-gastric route for measurement of gastric mucosal carbon dioxide partial pressure and calcula- 
tion of the gradient between gastric mucosal and partial pressure of arterial carbon dioxide [20,21].

Arterial blood samples were drawn and analyzed for $\mathrm{pH}$, arterial lactate, aspartate aminotransferase, alanine aminotransferase, total bilirubin (BILT), direct bilirubin (BILD), amylase, lipase, international normalized ratio, activated partial thromboplastin time ratio, cardiac troponin I, TNF- $\alpha$, IL-1 $\beta$, and IL-6. Urine samples were collected to assess urinary output and creatinine clearance.

\section{Study design}

Patients were randomized to one of three study groups using a computer-based procedure. Patients allocated to the TP group received a continuous TP infusion of $1.3 \mu \mathrm{g} / \mathrm{kg} / \mathrm{hour}$ and patients in the AVP group were treated with a continuous infusion of AVP at $0.03 \mathrm{U} / \mathrm{min}$. The control group received a fixed dose of NE (15 $\mu \mathrm{g} / \mathrm{min})$. In all three groups, open-label $\mathrm{NE}$ was additionally infused, if the goal MAP of $70 \pm 5 \mathrm{mmHg}$ was not achieved with study drug infusion alone (Figure 1).

Fluid challenge was performed to maintain central venous pressure at 8 to $12 \mathrm{mmHg}$ and PAOP between 12 and 18 $\mathrm{mmHg}$ during the 48-hour intervention period [3]. Packed red blood cells were transfused when hemogloblin concentrations decreased below $8 \mathrm{~g} / \mathrm{dL}$. If $\mathrm{SvO}_{2}$ was less than $65 \%$ despite appropriate arterial oxygenation (arterial oxygen saturation $\geq 95 \%$ ) and hemoglobin concentrations wer $8 \mathrm{~g} / \mathrm{dL}$ or above, dobutamine was administered in doses up to $20 \mu \mathrm{g} / \mathrm{kg} / \mathrm{min}$ to achieve $\mathrm{SvO}_{2}$ values of $65 \%$ or more, if possible [3]. During the 48-hour study period, all patients received intravenous hydrocortisone (200 mg/day) as a continuous infusion.
Systemic, pulmonary, and regional hemodynamic measurements, laboratory variables, blood gases as well as NE requirements, were determined at baseline, 12, 24, 36 and 48 hours after randomization. Plasma cytokine concentrations were measured at baseline and after 48 hours.

In patients surviving the 48-hour intervention period, study drug infusion was terminated, and open-label NE was titrated to maintain MAP at $70 \pm 5 \mathrm{mmHg}$. To assess the incidence of arterial rebound hypotension, NE infusion rates were again evaluated at 54 and 60 hours after randomization (i.e. 6 and 12 hours after termination of study drug infusion). None of the patients received further TP or AVP infusions.

\section{Statistical analysis}

The primary endpoint of the present study was the reduction of average open-label NE requirements in patients treated with TP as compared with the AVP or NE group. To detect a $30 \%$ difference in NE infusion rates between groups, with an expected standard deviation (SD) of $25 \%$ and a test power of the analysis of variance (ANOVA) of $80 \%$, a sample size of 15 individuals per group was required. Data are expressed as means $\pm S D$, if not otherwise specified. Sigma Stat 3.10 software (SPSS, Chicago, IL, USA) was used for statistical analysis. After confirming normal distribution of all variables (Kolmogorov-Smirnov test), differences within and among groups were analyzed using a two-way ANOVA for repeated measurements with group and time as factors. Time-independent variables were compared with one-way ANOVA. In case of significant group differences over time, appropriate post hoc comparisons (Student-Newman-Keuls) were performed. Categorical data were compared using the chi-squared test. For all

Figure 1

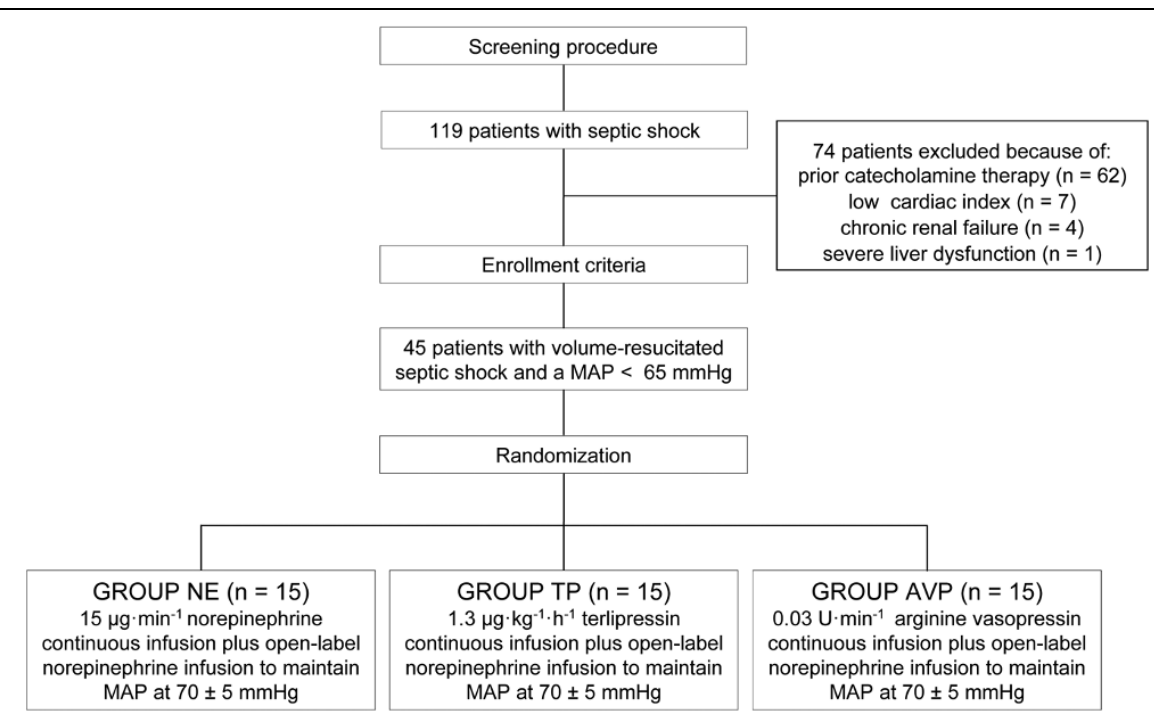

Study design. $\mathrm{AVP}=$ arginine vasopressin; $\mathrm{MAP}=$ mean arterial pressure; $\mathrm{NE}=$ norepinephrine; $\mathrm{TP}=$ terlipressin . 
tests, an $\alpha$-error probability of $P<0.05$ was considered as statistically significant.

\section{Results \\ Patients}

Of the 119 screened septic shock patients who met the inclusion criteria of the study, 74 had to be excluded due to prior catecholamine therapy $(n=62)$, inappropriately low cardiac output $(n=7)$, chronic renal failure $(n=4)$, and severe liver dysfunction $(n=1)$. Finally, 45 consecutive patients were enrolled in the study and equally randomized to one of the three study groups ( $n=15$ per group; Figure 1 ). None of the enrolled patients died during the study period.

\section{Demographic data}

Baseline characteristics including age, gender, body weight, origin of septic shock, and simplified acute physiology score II (SAPS II) are presented in Table 1. There were no significant differences in baseline characteristics between groups.

\section{Norepinephrine and dobutamine requirements}

Open-label NE infusion rates increased over time in the AVP and NE groups (each $P<0.001$ at 48 hours vs. baseline; Figure 2). Likewise, NE requirements increased during the first two hours of the study period in the TP group $(P<0.001)$. From 24 hours to the end of the intervention period, however, open-label NE infusion rates were significantly lower in the TP group as compared with the AVP and NE groups ( $P=0.02$ vs. AVP and $P<0.001$ vs. NE at 48 hours). In addition, NE requirements were significantly higher 12 hours after discontinuation of the study drugs in the NE and AVP group as compared with the TP group (each $P=0.018$ vs. AVP and NE at 60 hours). At six hours, dobutamine requirements were higher in TP-treated patients as compared with the other two groups.
However, thereafter dobutamine doses were similar between groups during the first 12 hours of initial hemodynamic resuscitation (Figure 3 ). Activated protein $\mathrm{C}$ was administered in four patients in NE group and in five patients in both TP and AVP groups.

\section{Systemic hemodynamic variables}

Systemic hemodynamic variables are summarized in Table 2. HR was significantly lower in the TP group as compared with the NE group over the whole interventional period $(P=0.047)$. There was no significant overall group difference in the other variables of systemic hemodynamics.

\section{New-onset tachyarrhythmias}

The incidence of new-onset tachyarrhythmias (i.e atrial fibrillation) was 0 of 15 in the TP group, 1 of 15 in the AVP group and 4 of 15 in patients allocated to the control group (not significant; $P=0.054$; chi-squared test).

\section{Acid-base homeostasis, oxygen transport variables}

There were no significant overall differences between groups in any variable of acid-base homeostasis or oxygen transport, except for a lower $\mathrm{pH}$ and base excess as well as a higher arterial lactate concentration in the NE as compared with the TP group at 48 hours (Table 3 ).

\section{Regional hemodynamics}

There were no significant overall differences between groups in any variable of regional hemodynamics. Nevertheless, a time-dependent decrease in PDR and $\mathrm{CBI}$ was observed in the AVP and NE groups (both $P<0.05$ at 48 hours vs. baseline; Table 4).

Table 1

Baseline characteristics, length of stay and outcome of the study patients

\begin{tabular}{|c|c|c|c|c|}
\hline & $\operatorname{TP}(n=15)$ & AVP $(n=15)$ & $\mathrm{NE}(n=15)$ & $P$ value \\
\hline Age, years & $67(60 ; 71)$ & $66(60 ; 74)$ & $64(59 ; 72)$ & 0.889 \\
\hline Gender, male & $73 \%$ & $67 \%$ & $80 \%$ & 0.717 \\
\hline Body weight, kg & $85(79 ; 100)$ & $85(71 ; 98)$ & $85(78 ; 90)$ & 0.612 \\
\hline SAPS II & $62(57 ; 72)$ & $60(49 ; 66)$ & $58(52 ; 68)$ & 0.664 \\
\hline \multirow[t]{4}{*}{ Cause of septic shock } & Necrotizing fasciitis $(n=1)$ & Endocarditis $(n=1)$ & Pancreatitis $(n=4)$ & 0.438 \\
\hline & Pancreatitis $(n=3)$ & Necrotizing fasciitis $(n=2)$ & Peritonitis $(n=6)$ & \\
\hline & Peritonitis $(n=5)$ & Peritonitis $(n=6)$ & Pneumonia $(n=5)$ & \\
\hline & Pneumonia $(n=6)$ & Pneumonia $(n=6)$ & & \\
\hline ICU mortality & $7 / 15$ & $8 / 15$ & $10 / 15$ & 0.533 \\
\hline ICU length of stay & $14(9 ; 25)$ & $17(5 ; 27)$ & $17(7 ; 23)$ & 0.878 \\
\hline
\end{tabular}

Data are given as median (25\%; $75 \%$ range).

AVP = arginine vasopressin; ICU = intensive care unit; NE = norepinephrine; TP = terlipressin; SAPS II = simplified acute physiology score II. 
Figure 2

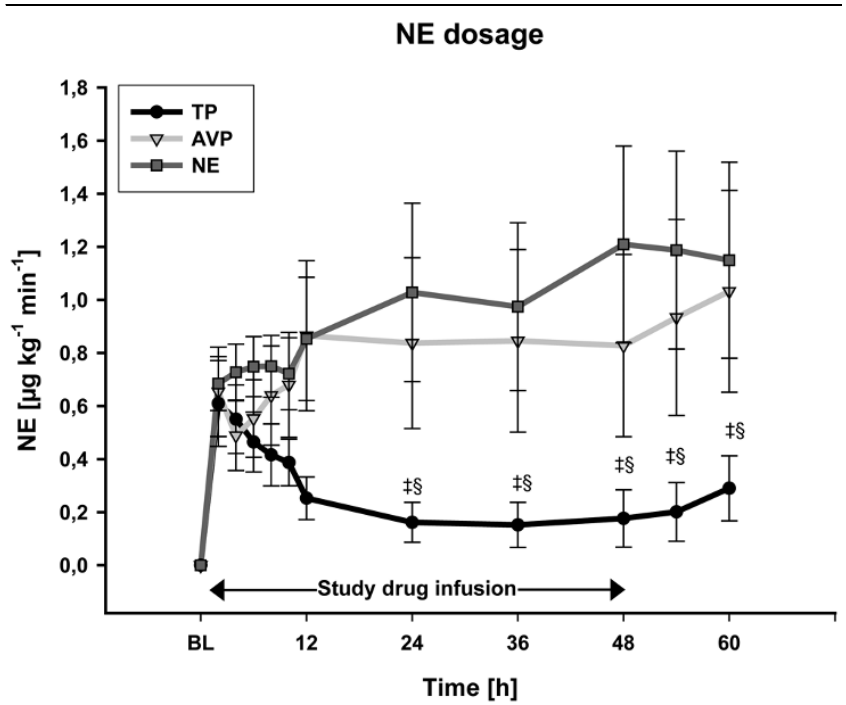

Norepinephrine requirements. AVP $=$ arginine vasopressin; $\mathrm{NE}=$ norepinephrine; TP $=$ terlipressin. ${ }^{\ddagger} P<0.05$ vs. AVP (significant group effect); $§ ~ P<0.05$ vs. NE (significant group effect).

\section{Variables of organ function and injury}

Variables of organ function and coagulation were similar between groups (Table 5), except for BILT and BILD, which were significantly higher in the AVP and NE group as compared with patients treated with TP at the end of the 48-hour intervention period (BILT: TP vs. NE, $P=0.001$; TP vs. AVP, $P=0.009$; BILD: TP vs. NE, $P=0.002$; TP vs. AVP, $P=$ 0.013).

\section{Figure 3}

Dobutamine dosage

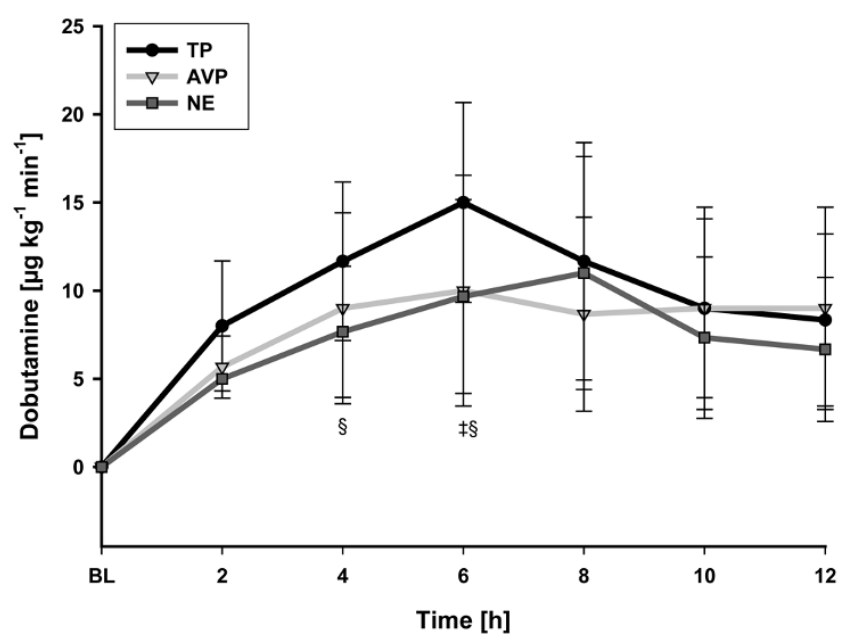

Dobutamine requirements. $A V P=$ arginine vasopressin; $M A P=$ mean arterial pressure; $\mathrm{NE}=$ norepinephrine; $\mathrm{TP}=$ terlipressin. ${ }^{\ddagger} P<0.05$ vs. AVP (significant group effect); $§ P<0.05$ vs. NE (significant group effect).
Creatinine plasma concentrations increased with time only in the NE group ( $P<0.001$ at 48 hours vs. baseline). The relative increase in creatinine concentrations over the 48-hour intervention period was significantly higher in the NE group as compared with the TP and AVP group (each $P<0.001$ ). Whereas 4 of $15(26.7 \%)$ and 5 of 15 (33.3\%) patients required renal replacement therapy at the end of the study period in the TP and AVP group, respectively, 8 of 15 patients (53.3\%) required renal replacement therapy at the end of the study period in the NE group (n.s.; $P=0.293$; chi-squared test). There were no differences in coagulation variables except for a time-dependent decrease in platelet count in the TP group ( $P<0.001$ at 48 hours vs. baseline).

\section{Markers of systemic inflammation}

IL-6 concentrations significantly decreased in the AVP group ( $P=0.044$ at 48 hours vs. baseline), and there was a strong tendency towards a decrease in the TP group $(P=0.052$ at 48 hours vs. baseline). However, there were no significant differences in TNF- $\alpha$ or IL-1 $\beta$ concentrations among groups (Table 6).

\section{Length of ICU stay and outcome}

Length of ICU stay and ICU mortality were similar between groups (Table 1).

\section{Discussion}

The major findings of the present study are that continuous, low-dose TP infusion at the investigated dose was effective in reversing sepsis-induced arterial hypotension and in reducing NE requirements.

In the current clinical trial, TP, AVP and NE - when administered as first-line vasopressor agents - were effective in increasing MAP to goal values of $70 \pm 5 \mathrm{mmHg}$ when combined with open-label NE. The vasoconstrictive effects of AVP and TP mainly depend on $V_{1}$ receptor stimulation. Nevertheless, AVP may also exert vasodilatory effects in a dosedependent manner, possibly mediated by nitric oxide liberation secondary to stimulation of $\mathrm{V}_{2}$ receptors [22]. In this context, Barrett and colleagues [23] recently reported that the selective $\mathrm{V}_{1}$ agonist $\mathrm{F}-180$ is a more effective vasoconstrictor agent as compared with AVP. The latter observation is in accordance with the finding of the present study that $T P$, a relatively selective $\mathrm{V}_{1}$ agonist as compared with AVP $\left(\mathrm{V}_{1}: \mathrm{V}_{2}\right.$ ratio of 2.2:1 vs. $1: 1$ ) [22], enabled a marked reduction in open-label NE requirements. As expected, due to its effective half-life of four to six hours, we noticed a longer duration of the TP effects (i.e. lack of rebound hypotension) [22].

The somewhat surprising observation of the present study that AVP only tended to but did not significantly reduce NE requirements is in contrast with the results of VASST (which used an identical vasopressin dose), in which AVP administration allowed a reduction in NE requirements [5]. However, there 
Critical Care Vol 13 No 4 Morelli et al.

Table 2

\section{Hemodynamic variables}

\begin{tabular}{|c|c|c|c|c|c|}
\hline & Baseline & 12 hours & 24 hours & 36 hours & 48 hours \\
\hline \multicolumn{6}{|c|}{$\begin{array}{l}\text { HR } \\
(\mathrm{bpm})\end{array}$} \\
\hline TP & $95 \pm 16$ & $85 \pm 19^{*}$ & $83 \pm 21^{*}$ & $71 \pm 14^{\star \neq \S}$ & $71 \pm 16^{\star} \star \S$ \\
\hline AVP & $100 \pm 22$ & $98 \pm 24$ & $97 \pm 27$ & $92 \pm 24^{\dagger}$ & $93 \pm 25^{\dagger}$ \\
\hline NE & $97 \pm 21$ & $92 \pm 26$ & $99 \pm 29$ & $95 \pm 24^{\dagger}$ & $96 \pm 21^{\dagger}$ \\
\hline \multicolumn{6}{|c|}{$\begin{array}{l}\mathrm{Cl} \\
(\mathrm{L} / \mathrm{min} / \mathrm{m})\end{array}$} \\
\hline TP & $4.0 \pm 1.0$ & $3.9 \pm 1.0$ & $3.7 \pm 0.8$ & $3.4 \pm 0.6$ & $3.5 \pm 0.6$ \\
\hline AVP & $4.0 \pm 1.1$ & $4.2 \pm 1.4$ & $4.3 \pm 1.1$ & $3.9 \pm 1.1$ & $4.2 \pm 1.9$ \\
\hline NE & $4.0 \pm 1.0$ & $3.9 \pm 1.0$ & $4.1 \pm 1.1$ & $3.9 \pm 1.2$ & $3.9 \pm 1.5$ \\
\hline \multicolumn{6}{|c|}{$\begin{array}{l}\text { SVI } \\
(\mathrm{mL} / \text { beats/m) }\end{array}$} \\
\hline TP & $46 \pm 13$ & $46 \pm 13$ & $47 \pm 12$ & $48 \pm 10$ & $50 \pm 10$ \\
\hline AVP & $41 \pm 12$ & $43 \pm 12$ & $46 \pm 10$ & $44 \pm 12$ & $47 \pm 18$ \\
\hline NE & $43 \pm 13$ & $44 \pm 14$ & $44 \pm 15$ & $43 \pm 16$ & $42 \pm 15$ \\
\hline \multicolumn{6}{|c|}{$\begin{array}{l}\text { MAP } \\
(\mathrm{mmHg})\end{array}$} \\
\hline TP & $53 \pm 6$ & $70 \pm 3^{*}$ & $71 \pm 3^{*}$ & $72 \pm 3^{*}$ & $71 \pm 4^{\star}$ \\
\hline AVP & $53 \pm 4$ & $70 \pm 3^{*}$ & $70 \pm 3^{*}$ & $71 \pm 3^{\star}$ & $71 \pm 3^{\star}$ \\
\hline NE & $54 \pm 3$ & $70 \pm 4^{*}$ & $71 \pm 2^{*}$ & $70 \pm 3^{*}$ & $71 \pm 3^{\star}$ \\
\hline \multicolumn{6}{|c|}{$\begin{array}{l}\text { MPAP } \\
(\mathrm{mmHg})\end{array}$} \\
\hline TP & $25 \pm 4$ & $27 \pm 4^{\star}$ & $27 \pm 4^{\star}$ & $27 \pm 5^{\star}$ & $28 \pm 5^{\star}$ \\
\hline AVP & $24 \pm 4$ & $28 \pm 5^{\star}$ & $28 \pm 5^{\star}$ & $28 \pm 5^{\star}$ & $29 \pm 4^{\star}$ \\
\hline NE & $24 \pm 7$ & $28 \pm 7^{\star}$ & $29 \pm 7^{\star}$ & $29 \pm 5^{*}$ & $30 \pm 7^{\star}$ \\
\hline \multicolumn{6}{|c|}{$\begin{array}{l}\text { PAOP } \\
(\mathrm{mmHg})\end{array}$} \\
\hline TP & $15 \pm 2$ & $17 \pm 2$ & $17 \pm 2$ & $17 \pm 2$ & $17 \pm 2$ \\
\hline AVP & $15 \pm 2$ & $17 \pm 2^{*}$ & $17 \pm 4^{*}$ & $17 \pm 3^{*}$ & $17 \pm 2^{\star}$ \\
\hline NE & $15 \pm 2$ & $15 \pm 2$ & $16 \pm 2$ & $16 \pm 2$ & $16 \pm 3$ \\
\hline \multicolumn{6}{|c|}{$\begin{array}{l}\text { RAP } \\
(\mathrm{mmHg})\end{array}$} \\
\hline TP & $11 \pm 3$ & $12 \pm 3$ & $14 \pm 3^{*}$ & $13 \pm 3$ & $13 \pm 3$ \\
\hline AVP & $12 \pm 3$ & $15 \pm 3^{*}$ & $14 \pm 3^{*}$ & $15 \pm 3^{*}$ & $15 \pm 4^{*}$ \\
\hline NE & $12 \pm 3$ & $13 \pm 3$ & $14 \pm 3$ & $14 \pm 4$ & $14 \pm 4$ \\
\hline
\end{tabular}




\begin{tabular}{|c|c|c|c|c|c|}
\hline \multicolumn{6}{|c|}{ Hemodynamic variables } \\
\hline TP & $886 \pm 291$ & $1271 \pm 334^{\star}$ & $1287 \pm 304^{*}$ & $1376 \pm 241^{*}$ & $1348 \pm 275^{*}$ \\
\hline AVP & $861 \pm 246$ & $1157 \pm 407^{\star}$ & $1091 \pm 325^{\star}$ & $1235 \pm 334^{*}$ & $1254 \pm 531^{*}$ \\
\hline NE & $874 \pm 220$ & $1237 \pm 320^{*}$ & $1208 \pm 348^{\star}$ & $1266 \pm 386^{*}$ & $1319 \pm 471^{*}$ \\
\hline \multicolumn{6}{|c|}{$\begin{array}{l}\text { PVRI } \\
\text { (dyne·s/cm/m) }\end{array}$} \\
\hline TP & $196 \pm 61$ & $227 \pm 99$ & $219 \pm 89$ & $256 \pm 108$ & $260 \pm 117$ \\
\hline AVP & $200 \pm 83$ & $243 \pm 108$ & $230 \pm 128$ & $254 \pm 148$ & $264 \pm 134$ \\
\hline NE & $192 \pm 115$ & $266 \pm 106^{*}$ & $275 \pm 122^{\star}$ & $298 \pm 133^{\star}$ & $313 \pm 202^{*}$ \\
\hline \multicolumn{6}{|c|}{$\begin{array}{l}\text { RVSWI } \\
\text { (g/m/beat) }\end{array}$} \\
\hline TP & $8 \pm 4$ & $9 \pm 4$ & $8 \pm 5$ & $9 \pm 4$ & $10 \pm 4$ \\
\hline AVP & $7 \pm 3$ & $8 \pm 3$ & $9 \pm 3^{*}$ & $8 \pm 3$ & $9 \pm 4^{\star}$ \\
\hline NE & $7 \pm 3$ & $9 \pm 4^{*}$ & $9 \pm 3^{\star}$ & $8 \pm 3^{\star}$ & $9 \pm 4^{\star}$ \\
\hline \multicolumn{6}{|c|}{$\begin{array}{l}\text { LVSWI } \\
\text { (g/m/beat) }\end{array}$} \\
\hline TP & $22 \pm 7$ & $33 \pm 9^{*}$ & $35 \pm 10^{*}$ & $37 \pm 8^{*}$ & $37 \pm 9^{\star}$ \\
\hline AVP & $21 \pm 7$ & $31 \pm 8^{*}$ & $32 \pm 6^{*}$ & $33 \pm 9^{*}$ & $34 \pm 14^{\star}$ \\
\hline NE & $22 \pm 7$ & $33 \pm 11^{*}$ & $33 \pm 12^{*}$ & $32 \pm 13^{*}$ & $31 \pm 11^{*}$ \\
\hline \multicolumn{6}{|c|}{$\begin{array}{l}\text { Fluids } \\
\text { (mL/24 h) }\end{array}$} \\
\hline TP & & & $4833 \pm 783$ & & $4353 \pm 853$ \\
\hline AVP & & & $4860 \pm 686$ & & $4513 \pm 781$ \\
\hline NE & & & $4707 \pm 860$ & & $4807 \pm 853$ \\
\hline
\end{tabular}

$\mathrm{AVP}=$ arginine vasopressin; $\mathrm{Cl}=$ cardiac index; $\mathrm{HR}=$ heart rate; LVSWI = left ventricular stroke work index; MAP = mean arterial pressure; $\mathrm{MPAP}=$ mean pulmonary arterial pressure; $\mathrm{NE}=$ norepinephrine; PAOP $=$ pulmonary artery occlusion pressure; PVRI $=$ pulmonary vascular resistance index; RAP = right atrial pressure; RVSWI = right ventricular stroke work index; SVI = stroke volume index; SVRI = systemic vascular resistance index; TP = terlipressin.

${ }^{\star} P<0.05$ vs. baseline (significant time effect); ${ }^{\dagger} P<0.05$ vs. TP (significant group effect); ${ }^{\ddagger} P<0.05$ vs. AVP (significant group effect); $\$ P<0.05$ vs. NE (significant group effect).

are several reasons that might explain this discrepancy. First, the considerably higher sample size of VASST as compared with the present study makes it more likely to detect significant differences. Moreover, in VASST [5], MAP at baseline was 72 to $73 \mathrm{mmHg}$, whereas it was considerably lower in the present study. Second, the mean time elapsed from meeting the criteria for study entry to infusion of AVP was 12 hours in VASST [5]. By contrast, in our study, a different hemodynamic condition at baseline (i.e. arterial hypotension), as well as the administration of AVP as a first-line therapy could have played a pivotal role in this regard [4]. In addition, the lack of reduction in NE requirements may potentially be explained by the low dose infused in the present study $(0.03 \mathrm{U} / \mathrm{min})$. Although previous studies suggest that AVP infusion in septic shock should not exceed $0.04 \mathrm{U} / \mathrm{min}$ because of the potential risk of adverse effects [3,24], Luckner and colleagues [25] recently reported that $0.067 \mathrm{U} / \mathrm{min}$ is more effective in hemodynamic support and catecholamine reduction than $0.033 \mathrm{U} / \mathrm{min}$. Finally, it has to be underlined that this specific dose has not yet been investigated as first-line therapy in the treatment of human septic shock. Therefore, it is possible that in the present study, TP was more effective than AVP because the TP dose was relatively higher as compared with the vasopressin dose.

In harmony with previous experimental and clinical studies [1114], we did not notice a decrease in $\mathrm{Cl}, \mathrm{DO}_{2} \mathrm{I}$ and $\mathrm{SvO}_{2}$ following low-dose AVP or TP infusion in fluid resuscitated septic shock patients. In this regard, it is important to underline that 
Critical Care Vol 13 No 4 Morelli et al.

Table 3

Oxygenation profile, acid-base variables and hemoglobin concentrations

\begin{tabular}{|c|c|c|c|c|c|}
\hline & Baseline & 12 hours & 24 hours & 36 hours & 48 hours \\
\hline \multicolumn{6}{|c|}{$\begin{array}{l}\text { PH } \\
\left(-\log _{10} \mathrm{c}\left(\mathrm{H}^{+}\right)\right)\end{array}$} \\
\hline TP & $7.31 \pm 0.1$ & $7.32 \pm 0.1$ & $7.32 \pm 0.1$ & $7.34 \pm 0.08$ & $7.37 \pm 0.08^{\star}$ \\
\hline AVP & $7.36 \pm 0.09$ & $7.35 \pm 0.11$ & $7.32 \pm 0.12$ & $7.34 \pm 0.12$ & $7.32 \pm 0.11$ \\
\hline NE & $7.34 \pm 0.1$ & $7.34 \pm 0.08$ & $7.32 \pm 0.08$ & $7.31 \pm 0.09$ & $7.28 \pm 0.12^{\star+}$ \\
\hline \multicolumn{6}{|c|}{$\mathrm{PaO}_{2} / \mathrm{FiO}_{2}$} \\
\hline TP & $176 \pm 105$ & $179 \pm 82$ & $189 \pm 86$ & $216 \pm 95$ & $220 \pm 78$ \\
\hline AVP & $219 \pm 118$ & $231 \pm 117$ & $222 \pm 129$ & $211 \pm 132$ & $225 \pm 133$ \\
\hline NE & $200 \pm 97$ & $216 \pm 113$ & $213 \pm 101$ & $194 \pm 73$ & $185 \pm 85$ \\
\hline \multicolumn{6}{|c|}{$\begin{array}{l}\mathrm{PaO}_{2} \\
(\mathrm{mmHg})\end{array}$} \\
\hline TP & $113 \pm 44$ & $127 \pm 45$ & $141 \pm 47$ & $164 \pm 66$ & $175 \pm 64$ \\
\hline AVP & $123 \pm 36$ & $140 \pm 48$ & $130 \pm 49$ & $127 \pm 59$ & $139 \pm 58$ \\
\hline NE & $120 \pm 46$ & $124 \pm 44$ & $125 \pm 31$ & $123 \pm 34$ & $114 \pm 49$ \\
\hline \multicolumn{6}{|c|}{$\begin{array}{l}\mathrm{pvO}_{2} \\
(\mathrm{mmHg})\end{array}$} \\
\hline TP & $36 \pm 6$ & $36 \pm 6$ & $36 \pm 5$ & $35 \pm 5$ & $36 \pm 5$ \\
\hline AVP & $35 \pm 6$ & $38 \pm 6$ & $38 \pm 5$ & $38 \pm 6$ & $38 \pm 6$ \\
\hline NE & $36 \pm 7$ & $38 \pm 6$ & $38 \pm 6$ & $39 \pm 7$ & $38 \pm 6$ \\
\hline \multicolumn{6}{|c|}{$\begin{array}{l}\mathrm{SaO}_{2} \\
(\%)\end{array}$} \\
\hline TP & $96 \pm 4$ & $97 \pm 3$ & $98 \pm 2$ & $99 \pm 2$ & $99 \pm 2$ \\
\hline AVP & $97 \pm 3$ & $98 \pm 3$ & $98 \pm 2$ & $96 \pm 4$ & $98 \pm 2$ \\
\hline $\mathrm{NE}$ & $97 \pm 2$ & $96 \pm 7$ & $98 \pm 1$ & $98 \pm 2$ & $96 \pm 7$ \\
\hline \multicolumn{6}{|c|}{$\begin{array}{l}\mathrm{SvO}_{2} \\
(\%)\end{array}$} \\
\hline TP & $60 \pm 7$ & $59 \pm 11$ & $60 \pm 9$ & $60 \pm 8$ & $63 \pm 8$ \\
\hline AVP & $61 \pm 12$ & $65 \pm 11$ & $64 \pm 7$ & $63 \pm 13$ & $64 \pm 12$ \\
\hline NE & $62 \pm 10$ & $66 \pm 10$ & $66 \pm 9$ & $66 \pm 9$ & $62 \pm 12$ \\
\hline \multicolumn{6}{|c|}{$\begin{array}{l}\mathrm{DO}_{2} \mathrm{I} \\
(\mathrm{mL} / \mathrm{min} / \mathrm{m})\end{array}$} \\
\hline TP & $473 \pm 105$ & $468 \pm 117$ & $433 \pm 92$ & $393 \pm 73$ & $402 \pm 70$ \\
\hline AVP & $464 \pm 137$ & $519 \pm 189$ & $550 \pm 165$ & $484 \pm 123$ & $520 \pm 242$ \\
\hline NE & $460 \pm 131$ & $471 \pm 157$ & $482 \pm 136$ & $462 \pm 136$ & $467 \pm 162$ \\
\hline \multicolumn{6}{|c|}{$\begin{array}{l}\mathrm{VO}_{2} \mathrm{I} \\
(\mathrm{mL} / \mathrm{min} / \mathrm{m})\end{array}$} \\
\hline TP & $184 \pm 58$ & $184 \pm 49$ & $171 \pm 32$ & $160 \pm 43$ & $152 \pm 38$ \\
\hline AVP & $173 \pm 51$ & $173 \pm 59$ & $193 \pm 65$ & $168 \pm 52$ & $173 \pm 51$ \\
\hline NE & $163 \pm 41$ & $147 \pm 35$ & $160 \pm 57$ & $153 \pm 51$ & $164 \pm 67$ \\
\hline \multicolumn{6}{|c|}{$\begin{array}{l}\mathrm{O}_{2} \text {-ER } \\
(\%)\end{array}$} \\
\hline TP & $38 \pm 6$ & $40 \pm 9$ & $40 \pm 8$ & $41 \pm 8$ & $38 \pm 8$ \\
\hline AVP & $39 \pm 12$ & $35 \pm 9$ & $35 \pm 6$ & $36 \pm 11$ & $37 \pm 10$ \\
\hline
\end{tabular}




\begin{tabular}{|c|c|c|c|c|c|}
\hline NE & $37 \pm 10$ & $32 \pm 6$ & $34 \pm 9$ & $34 \pm 9$ & $36 \pm 10$ \\
\hline \multicolumn{6}{|c|}{$\begin{array}{l}\mathrm{PaCO}_{2} \\
(\mathrm{mmHg})\end{array}$} \\
\hline TP & $45 \pm 6$ & $42 \pm 6$ & $41 \pm 9$ & $40 \pm 8$ & $38 \pm 6$ \\
\hline AVP & $43 \pm 9$ & $40 \pm 5$ & $42 \pm 4$ & $41 \pm 6$ & $41 \pm 6$ \\
\hline $\mathrm{NE}$ & $44 \pm 9$ & $43 \pm 9$ & $44 \pm 8$ & $44 \pm 8$ & $43 \pm 9$ \\
\hline \multicolumn{6}{|c|}{$\begin{array}{l}\text { ABE } \\
(\mathrm{mmol} / \mathrm{L})\end{array}$} \\
\hline TP & $-2.9 \pm 5.1$ & $-4.6 \pm 4.2$ & $-4.9 \pm 4.6$ & $-4.0 \pm 4.2$ & $-3.1 \pm 4.2$ \\
\hline AVP & $-1.8 \pm 6.5$ & $-2.8 \pm 7.0$ & $-3.7 \pm 6.7$ & $-1.6 \pm 7.8$ & $-4.1 \pm 6.5$ \\
\hline NE & $-2.5 \pm 4.5$ & $-2.5 \pm 4.3$ & $-3.5 \pm 4.3$ & $-4.2 \pm 3.9$ & $-6.2 \pm 5.4^{\star}$ \\
\hline \multicolumn{6}{|c|}{$\begin{array}{l}\text { Arterial lactate } \\
(\mathrm{mmol} / \mathrm{L})\end{array}$} \\
\hline TP & $3.1 \pm 1.8$ & $2.9 \pm 1.9$ & $2.9 \pm 2.0$ & $3.4 \pm 2.4$ & $3.6 \pm 3.0$ \\
\hline AVP & $3.0 \pm 2.4$ & $3.2 \pm 2.3$ & $3.4 \pm 2.3$ & $3.2 \pm 2.3$ & $3.4 \pm 3.3$ \\
\hline NE & $3.1 \pm 2.2$ & $3.3 \pm 2.8$ & $3.4 \pm 2.8$ & $3.6 \pm 2.4$ & $4.3 \pm 3.4^{\star}$ \\
\hline \multicolumn{6}{|c|}{$\begin{array}{l}\text { Hemoglobin } \\
(\mathrm{g} / \mathrm{dL})\end{array}$} \\
\hline TP & $8.6 \pm 0.9$ & $8.7 \pm 0.7$ & $8.4 \pm 1.2$ & $8.2 \pm 0.6^{\ddagger}$ & $8.1 \pm 0.6$ \\
\hline AVP & $8.3 \pm 0.9$ & $8.7 \pm 1.1$ & $9 \pm 1.1^{*}$ & $9 \pm 1^{\text {*t }}$ & $8.8 \pm 0.9$ \\
\hline NE & $8.3 \pm 0.8$ & $8.7 \pm 0.9$ & $8.4 \pm 0.5$ & $8.5 \pm 0.8$ & $8.9 \pm 1$ \\
\hline
\end{tabular}

$\mathrm{ABE}=$ arterial base excess; $\mathrm{AVP}=$ arginine vasopressin; $\mathrm{DO}_{2} \mathrm{I}=$ oxygen delivery index; $\mathrm{NE}=$ norepinephrine; $\mathrm{O}_{2}$-ER $=$ oxygen extraction rate; $\mathrm{PaCO}_{2}=$ partial pressure of arterial carbon dioxide; $\mathrm{PaO}_{2} / \mathrm{FiO}_{2}=$ ratio of oxygen tension over inspired oxygen concentration; $\mathrm{PaO}_{2}=$ partial pressure of arterial oxygen; $\mathrm{pH}=$ arterial $\mathrm{pH} ; \mathrm{pvO}_{2}=$ mixed venous oxygen tension; $\mathrm{SaO}_{2}=$ arterial oxygen saturation; $\mathrm{SvO} \mathrm{O}_{2}=$ mixed venous oxygen saturation; $\mathrm{VO}_{2} \mathrm{l}=$ oxygen consumption index; $\mathrm{TP}=$ terlipressin.

${ }^{*} P<0.05$ vs. baseline (significant time effect); ${ }^{\dagger} P<0.05$ vs. TP (significant group effect); ${ }^{\ddagger} P<0.05$ vs. AVP (significant group effect); $\S P<0.05$ vs. NE (significant group effect).

dobutamine doses administered to achieve $\mathrm{SvO}_{2}$ values of $65 \%$ or moreduring the initial phase of hemodynamic resuscitation were similar between groups. In addition, neither AVP nor TP negatively affected pulmonary hemodynamics and function, as suggested by constant PVRI values and partial pressure of arterial oxygen $\left(\mathrm{PaO}_{2}\right)$ /fraction of inspired oxygen $\left(\mathrm{FiO}_{2}\right)$ ratio. These findings confirm the theory that continuous TP infusion may be favourable over TP bolus infusion, because the latter approach has been reported to excessively increase SVRI and PVRI, as well as to decrease HR and $\mathrm{Cl}$ [11].

Previous studies investigating low-dose AVP or TP in patients with septic shock following adequate fluid resuscitation reported few or no unwanted side effects within the splanchnic circulation [7,26-29]. In agreement with these previous studies, we did not find significant overall differences among groups in terms of arterial lactate concentrations or acid-base homeostasis, as well as surrogate markers of splanchnic perfusion. The absence of detrimental hepatosplanchnic hemodynamic effects of TP and AVP during the observation period is further confirmed by the lack of significant overall differences among groups in terms of liver and pancreatic enzymes. Nev- ertheless, at the end of the study period, both BILT and BILD were significantly higher in both the AVP and NE group as compared with patients treated with TP. The increase in BILT in the AVP group noticed in the present study is in agreement with previous studies $[25,27,30]$ reporting similar findings after AVP administration. In contrast, we did not find any differences in BILT 48 hours after TP administration. It has been postulated that AVP might contribute to an increase in BILT concentrations by a reduction of biliary output and bile flow after an initial transient increase [31]. In addition, it has been shown that AVP may modulate hepatocyte tight junctional permeability and thus produce cholestasis [32]. Although speculative, it is possible that these effects are less pronounced when TP is administered, probably due to its higher $\mathrm{V}_{1}$ selectivity. Nevertheless, the implication of this finding for the course of the disease remains uncertain and should be clarified in future studies.

Although AVP may contribute to antidiuresis in a dosedependent manner [33], recent studies revealed that in the presence of septic shock, vasopressin analogues may increase diuresis and improve renal function [7- 
Table 4

\begin{tabular}{|c|c|c|c|c|c|}
\hline & Baseline & 12 hours & 24 hours & 36 hours & 48 hours \\
\hline \multicolumn{6}{|c|}{$\begin{array}{l}\text { CBI } \\
(\mathrm{mL} / \mathrm{min} / \mathrm{m})\end{array}$} \\
\hline TP & $353 \pm 226$ & $387 \pm 202$ & $367 \pm 179$ & $299 \pm 139$ & $351 \pm 129$ \\
\hline AVP & $397 \pm 171$ & $409 \pm 209$ & $367 \pm 222$ & $308 \pm 185^{\star}$ & $305 \pm 201^{*}$ \\
\hline NE & $327 \pm 135$ & $358 \pm 173$ & $312 \pm 145$ & $271 \pm 136$ & $252 \pm 206$ \\
\hline \multicolumn{6}{|l|}{$\begin{array}{l}\text { PDR } \\
(\%)\end{array}$} \\
\hline TP & $13 \pm 6$ & $14 \pm 5$ & $13 \pm 4$ & $12 \pm 5$ & $13 \pm 4$ \\
\hline AVP & $15 \pm 5$ & $15 \pm 6$ & $13 \pm 7$ & $12 \pm 7^{\star}$ & $11 \pm 6^{*}$ \\
\hline NE & $14 \pm 5$ & $13 \pm 5$ & $12 \pm 6$ & $11 \pm 6^{*}$ & $10 \pm 7^{*}$ \\
\hline \multicolumn{6}{|c|}{$\underset{(\mathrm{mmHg})}{\mathrm{P}_{\mathrm{g}-\mathrm{CO}} \mathrm{CO}_{2}}$} \\
\hline TP & $23 \pm 11$ & $24 \pm 8$ & $22 \pm 6$ & $20 \pm 6$ & $20 \pm 7$ \\
\hline AVP & $25 \pm 7$ & $28 \pm 8$ & $27 \pm 9$ & $28 \pm 12$ & $28 \pm 10$ \\
\hline NE & $24 \pm 11$ & $28 \pm 10$ & $28 \pm 8$ & $26 \pm 8$ & $31 \pm 12$ \\
\hline \multicolumn{6}{|c|}{$\begin{array}{l}\text { Urinary output } \\
(\mathrm{mL} / \mathrm{h})\end{array}$} \\
\hline TP & $34.6 \pm 31.3$ & $69.3 \pm 70.4$ & $49.2 \pm 49.5$ & $48.5 \pm 41.4$ & $46.6 \pm 33.3$ \\
\hline AVP & $42.3 \pm 46.9$ & $42 \pm 39$ & $42 \pm 41.6$ & $40.7 \pm 45.7$ & $43.3 \pm 58.7$ \\
\hline NE & $38.6 \pm 34.3$ & $55.4 \pm 74.1$ & $66 \pm 77$ & $58.6 \pm 56.1$ & $58.6 \pm 63.8$ \\
\hline
\end{tabular}

$\mathrm{AVP}=$ arginine vasopressin; $\mathrm{CBI}=$ blood clearance of indocyanine green; $\mathrm{NE}=$ norepinephrine; $\mathrm{PDR}=$ plasma disappearance rate of indocyanine green; $\mathrm{P}_{\mathrm{g}-\mathrm{a}} \mathrm{CO}_{2}=$ gastric-mucosal arterial carbon dioxide partial pressure difference; TP $=$ terlipressin.

${ }^{\star} P<0.05$ vs. baseline (significant time effect); ${ }^{\dagger} P<0.05$ vs. TP (significant group effect); ${ }^{\ddagger} P<0.05$ vs. AVP (significant group effect); $\$ P<0.05$ vs. NE (significant group effect).

$9,24,26,28,29]$. Different pharmacological effects on the afferent and efferent arterioles [34], as well as the pathophysiological features in vasopressin receptor physiology in sepsis [35] may account for these observations [7-9,24,26,28,29]. Moreover, the AVP-associated increase in systemic blood pressure may contribute to an increase in urine output [36]. Notably, a post hoc analysis of the VASST data [37] demonstrated a reduced rate of progression to acute renal failure in patients at risk for acute renal failure ('R', according to the RIFLE criteria [38]) treated with AVP. In harmony with the latter observation [37], neither AVP nor TP negatively affected renal function in the present study.

AVP has been reported to activate platelets via $V_{1}$ receptors, leading to an increase in CD62 expression $[39,40]$ and a decrease in platelet count in patients with normal platelets, but not in patients with low platelets [39]. In this context, it is another interesting finding of the present study that TP, as compared with AVP and NE, significantly decreased platelet count. However, in accordance with a previous study [40], neither AVP nor NE negatively affected the coagulation system.

The present study has some limitations that we would like to acknowledge. First, because there are no equivalent doses or data comparing different doses of AVP and TP, we decided to evaluate the efficacy of fixed doses of the study drugs in reaching the threshold MAP and to investigate their effects on openlabel NE requirements. We therefore chose the AVP dose investigated in VASST (i.e. $0.03 \mathrm{U} / \mathrm{min}$ of AVP and $15 \mu \mathrm{g} / \mathrm{min}$ of NE) [5] and a low TP dose previously reported to be safe and effective in a case series [13]. In this regard, it needs to be considered that AVP was administered at a fixed dose of 
Table 5

Surrogate variables of organ function and injury

\begin{tabular}{|c|c|c|c|c|c|}
\hline & Baseline & 12 hours & 24 hours & 36 hours & 48 hours \\
\hline \multicolumn{6}{|c|}{$\begin{array}{l}\text { Creatinine } \\
\text { (mg/dL) }\end{array}$} \\
\hline TP & $2.5 \pm 1$ & $2.6 \pm 1.2$ & $2.8 \pm 1.4$ & $2.8 \pm 1.3$ & $2.8 \pm 1.4$ \\
\hline AVP & $2.2 \pm 1$ & $2.4 \pm 1.1$ & $2.4 \pm 1.2$ & $2.5 \pm 1.4$ & $2.4 \pm 1.2$ \\
\hline NE & $2.2 \pm 1.6$ & $2.6 \pm 1.7$ & $2.7 \pm 1.7^{\star}$ & $2.9 \pm 1.8^{*}$ & $3.3 \pm 2^{*}$ \\
\hline \multicolumn{6}{|c|}{$\begin{array}{l}\text { Creatinine, rel. } \\
(\%)\end{array}$} \\
\hline TP & -- & $4 \pm 16$ & $11 \pm 23$ & $13 \pm 27$ & $14 \pm 35 \S$ \\
\hline AVP & -- & $11 \pm 17$ & $12 \pm 26$ & $15 \pm 31$ & $10 \pm 21^{\S}$ \\
\hline NE & -- & $19 \pm 23$ & $23 \pm 37$ & $34 \pm 48$ & $54 \pm 77^{\dagger \neq}$ \\
\hline \multicolumn{6}{|c|}{$\begin{array}{l}\text { Bilirubin, tot. } \\
\text { (mg/dL) }\end{array}$} \\
\hline TP & $1.2 \pm 0.7$ & $1 \pm 0.5$ & $1 \pm 0.5$ & $0.9 \pm 0.3^{\ddagger \S}$ & $0.9 \pm 0.3^{\ddagger \S}$ \\
\hline AVP & $1.6 \pm 1.3$ & $1.6 \pm 1.2$ & $1.8 \pm 1.6$ & $2.0 \pm 2.0^{+}$ & $2.3 \pm 2.8^{\dagger}$ \\
\hline NE & $1.6 \pm 0.9$ & $1.9 \pm 0.8$ & $2.0 \pm 1.2$ & $2.3 \pm 1.7^{\star \dagger}$ & $2.8 \pm 2.5^{\star+}$ \\
\hline \multicolumn{6}{|c|}{$\begin{array}{l}\text { Bilirubin, dir. } \\
\text { (mg/dL) }\end{array}$} \\
\hline TP & $0.5 \pm 0.3$ & $0.5 \pm 0.4$ & $0.5 \pm 0.3$ & $0.4 \pm 0.2^{\S}$ & $0.3 \pm 0.1^{\ddagger \S}$ \\
\hline AVP & $0.8 \pm 0.9$ & $1 \pm 1.2$ & $1.1 \pm 1.4$ & $1.1 \pm 1.5$ & $1.4 \pm 1.9^{\star \star}$ \\
\hline NE & $0.8 \pm 0.5$ & $1.2 \pm 0.8$ & $1.2 \pm 0.9$ & $1.6 \pm 1.7^{\star \star \dagger}$ & $1.9 \pm 2.1^{\text {*十 }}$ \\
\hline \multicolumn{6}{|c|}{$\begin{array}{l}\text { ASAT } \\
(\mathrm{U} / \mathrm{L})\end{array}$} \\
\hline TP & $52 \pm 26$ & $52 \pm 33$ & $54 \pm 35$ & $53 \pm 42$ & $48 \pm 34$ \\
\hline AVP & $63 \pm 49$ & $85 \pm 57$ & $79 \pm 66$ & $119 \pm 163$ & $91 \pm 95$ \\
\hline NE & $72 \pm 68$ & $89 \pm 115$ & $95 \pm 132$ & $103 \pm 146$ & $90 \pm 122$ \\
\hline \multicolumn{6}{|c|}{$\begin{array}{l}\text { ALAT } \\
\text { (U/L) }\end{array}$} \\
\hline TP & $30 \pm 14$ & $34 \pm 15$ & $33 \pm 14$ & $35 \pm 18$ & $30 \pm 13$ \\
\hline AVP & $45 \pm 31$ & $58 \pm 42$ & $63 \pm 53$ & $69 \pm 67$ & $81 \pm 85$ \\
\hline NE & $43 \pm 45$ & $62 \pm 80$ & $68 \pm 103$ & $73 \pm 114$ & $63 \pm 97$ \\
\hline \multicolumn{6}{|c|}{$\begin{array}{l}\text { Amylase } \\
(\mathrm{U} / \mathrm{L})\end{array}$} \\
\hline TP & $168 \pm 97$ & $148 \pm 90$ & $133 \pm 79$ & $127 \pm 79$ & $144 \pm 124$ \\
\hline AVP & $165 \pm 111$ & $152 \pm 100$ & $143 \pm 79$ & $147 \pm 110$ & $123 \pm 70$ \\
\hline NE & $203 \pm 191$ & $199 \pm 182$ & $217 \pm 221$ & $206 \pm 212$ & $172 \pm 152$ \\
\hline \multicolumn{6}{|c|}{$\begin{array}{l}\text { Lipase } \\
(\mathrm{U} / \mathrm{L})\end{array}$} \\
\hline TP & $138 \pm 145$ & $125 \pm 92$ & $97 \pm 64$ & $144 \pm 126$ & $116 \pm 91$ \\
\hline AVP & $133 \pm 90$ & $124 \pm 68$ & $127 \pm 64$ & $136 \pm 72$ & $134 \pm 65$ \\
\hline NE & $134 \pm 160$ & $198 \pm 282$ & $120 \pm 96$ & $158 \pm 162$ & $115 \pm 65$ \\
\hline \multicolumn{6}{|c|}{$\begin{array}{l}\text { Troponine I } \\
(\mathrm{ng} / \mathrm{mL})\end{array}$} \\
\hline TP & $0.31 \pm 0.3$ & $0.31 \pm 0.51$ & $0.22 \pm 0.41$ & $0.19 \pm 0.35$ & $0.18 \pm 0.3$ \\
\hline
\end{tabular}


Table 5 (Continued)

\begin{tabular}{|c|c|c|c|c|c|}
\hline AVP & $0.56 \pm 1$ & $0.84 \pm 1.5$ & $1.23 \pm 2.4$ & $1.37 \pm 2.5$ & $1.17 \pm 2$ \\
\hline NE & $0.58 \pm 0.9$ & $0.66 \pm 0.8$ & $0.72 \pm 0.75$ & $0.69 \pm 0.86$ & $0.63 \pm 1$ \\
\hline \multicolumn{6}{|c|}{$\begin{array}{l}\text { Platelet count } \\
\left(10^{3} \text { cells } / \mu \mathrm{L}\right)\end{array}$} \\
\hline TP & $119 \pm 68$ & $103 \pm 59$ & $93 \pm 59^{*}$ & $78 \pm 48^{*}$ & $73 \pm 41^{*}$ \\
\hline AVP & $110 \pm 56$ & $102 \pm 63$ & $95 \pm 53$ & $95 \pm 55$ & $93 \pm 50$ \\
\hline NE & $114 \pm 64$ & $102 \pm 52$ & $99 \pm 58$ & $94 \pm 60$ & $94 \pm 69$ \\
\hline \multicolumn{6}{|l|}{ INR } \\
\hline TP & $1.4 \pm 0.2$ & $1.4 \pm 0.2$ & $1.4 \pm 0.2$ & $1.4 \pm 0.2$ & $1.4 \pm 0.2$ \\
\hline AVP & $1.5 \pm 0.5$ & $1.5 \pm 0.3$ & $1.5 \pm 0.5$ & $1.5 \pm 0.4$ & $1.5 \pm 0.5$ \\
\hline NE & $1.5 \pm 0.3$ & $1.5 \pm 0.3$ & $1.4 \pm 0.4$ & $1.3 \pm 0.2$ & $1.4 \pm 0.3$ \\
\hline \multicolumn{6}{|c|}{ APTTr } \\
\hline TP & $1.7 \pm 0.6$ & $1.6 \pm 0.5$ & $1.6 \pm 0.4$ & $1.8 \pm 0.6$ & $1.7 \pm 0.7$ \\
\hline AVP & $1.5 \pm 0.5$ & $1.5 \pm 0.6$ & $1.6 \pm 0.7$ & $1.6 \pm 0.7$ & $1.7 \pm 0.7$ \\
\hline NE & $1.5 \pm 0.2$ & $1.4 \pm 0.2$ & $1.4 \pm 0.2$ & $1.4 \pm 0.2$ & $1.6 \pm 0.3$ \\
\hline
\end{tabular}

ALAT = alanine aminotransferase $;$ aPTTr $=$ activated partial thromboplastin time ratio; ASAT $=$ aspartate aminotransferase; AVP $=$ arginine vasopressin; Creatinine rel = relative increase in creatinine concentrations from baseline; INR $=$ international normalized ratio; $N E=$ norepinephrine; TP $=$ terlipressin.

${ }^{\star} P<0.05$ vs. baseline (significant time effect); ${ }^{\dagger} P<0.05$ vs. TP (significant group effect); ${ }^{\ddagger} P<0.05$ vs. AVP (significant group effect); $\$ P<0.05$ vs. NE (significant group effect).

0.03.U/min. It might be argued that a weight-adjusted TP dose was compared with a fixed AVP dose and thus the chosen doses might not have been pharmacologically equivalent. Therefore, it is possible that the TP dose was relatively higher as compared with the AVP dose.

Second, we performed a pilot study with the reduction of open-label NE requirements as the primary endpoint. In this regard, it has to be underlined that there is no reliable evidence that a reduction in catecholamine requirements may lead to an improved outcome. Third, we investigated only a small number of septic shock patients treated over a relative brief period. In this regard, the risk of positive results in a study with numerous secondary variables and time points has to be taken into account. Thus, caution should be exercised in interpreting the results of the secondary outcome variables. Properly powered, randomized controlled trials are required to determine the effects of TP infusion on clinical outcome. All patients included in the present study received hydrocortisone, so we cannot judge if and how corticosteroids affected our results $[41,42]$. For safety reasons, we opted for a 48-hour intervention period, because it was impossible to measure the circulating levels of TP. Although there is no evidence of drug accumulation over time, we cannot rule out this possibility when TP is infused over a more prolonged period. Moreover, hepatosplanchnic perfusion was assessed using PDR and CBI. Although PDR and $\mathrm{CBI}$ have been found to be a good predictor of survival in critically ill patients, at best it reflects the total splanchnic blood flow without separating hepatic arterial from portal venous flow. In addition, mucosal blood flow was estimated by gastric tonometry, a methodology that does not necessarily reflect changes in other parts of the gastrointestinal tract.

\section{Conclusions}

Taken together, our results demonstrate that a continuous infusion of a relatively low dose of TP $(1.3 \mu \mathrm{g} / \mathrm{kg} / \mathrm{h})$ was effective in reversing sepsis-induced hypotension and in reducing NE requirements. Larger randomized controlled clinical trials are necessary to explicitly clarify whether or not low-dose TP infusion may improve the overall outcome of patients with septic shock as compared with standard therapy. Awaiting these results, continuous TP infusion should not be routinely used outside the scope of controlled clinical trials and might be considered as a rescue therapy, when catecholamines are no longer effective.

\section{Competing interests}

The authors declare that they have no competing interests. 


\begin{tabular}{|c|c|c|}
\hline & Baseline & 48 hours \\
\hline \multicolumn{3}{|c|}{$\begin{array}{l}\text { IL-6 } \\
(\mathrm{pg} / \mathrm{mL})\end{array}$} \\
\hline TP & $612 \pm 640$ & $296 \pm 367$ \\
\hline AVP & $621 \pm 595$ & $293 \pm 324$ * \\
\hline NE & $655 \pm 585$ & $380 \pm 251$ \\
\hline \multicolumn{3}{|c|}{$\begin{array}{l}\mathrm{IL}-1 \beta \\
(\mathrm{pg} / \mathrm{mL})\end{array}$} \\
\hline TP & $6.6 \pm 0.6$ & $6.1 \pm 0.6$ \\
\hline AVP & $6.7 \pm 1$ & $6.5 \pm 1$ \\
\hline NE & $6.5 \pm 0.7$ & $6.6 \pm 0.7$ \\
\hline \multicolumn{3}{|c|}{$\begin{array}{l}\text { TNF- } \alpha \\
\text { (pg/mL) }\end{array}$} \\
\hline TP & $24 \pm 21$ & $18 \pm 6$ \\
\hline AVP & $24 \pm 16$ & $24 \pm 27$ \\
\hline NE & $28 \pm 15$ & $29 \pm 21$ \\
\hline \multicolumn{3}{|c|}{$\begin{array}{l}\text { Temperature } \\
\left({ }^{\circ} \mathrm{C}\right)\end{array}$} \\
\hline TP & $38.6 \pm 2$ & $37.8 \pm 0.8$ \\
\hline AVP & $39 \pm 0.4$ & $38.2 \pm 1$ \\
\hline NE & $38.8 \pm 0.2$ & $38.5 \pm 0.8$ \\
\hline
\end{tabular}

$\mathrm{AVP}=$ arginine vasopressin; $\mathrm{NE}=$ norepinephrine; $\mathrm{TP}=$ terlipressin.

${ }^{*} P<0.05$ vs. baseline (significant time effect).

\section{Key messages}

- Continuous infusion of low-dose TP - when given as first-line vasopressor agent in septic shock - reduces open-label NE requirements.

- Low-dose AVP or TP infusion do not decrease in $\mathrm{Cl}$, $\mathrm{DO}_{2} \mathrm{I}$ and $\mathrm{SvO}_{2}$ in adequately fluid resuscitated septic shock patients.

- Continuous TP infusion may be favourable over TP bolus infusion, because the latter approach has been reported to excessively increase SVRI and PVRI as well as decreases in $\mathrm{HR}$ and $\mathrm{Cl}$.

- Neither AVP nor TP negatively affected pulmonary hemodynamics and function.

- There are no differences between TP, AVP and NE in terms of regional hemodynamics or acid-base homeostasis when they are administered as first-line vasopressor agent in septic shock.

\section{Authors' contributions}

$\mathrm{AM}$ and $\mathrm{MW}$ were responsible for the study design and coordination and drafted the manuscript. CE, ML, SR and HVA par- ticipated in the design of the study, performed the statistical analysis and helped to draft the manuscript. AO and VC participated in the study design and helped to draft the manuscript. $A B$ and MD participated in the study design, performed laboratory measurements and helped to draft the manuscript. PP participated in the study design and coordination and helped to draft the manuscript and obtained funding. All authors listed on the title page read and approved the final manuscript.

\section{Acknowledgements}

This study was funded by an independent research grant from the Department of Anesthesiology and Intensive Care of the University of Rome 'La Sapienza'.

\section{References}

1. Rivers E, Nguyen B, Havstad S, Ressler J, Muzzin A, Knoblich B, Peterson E, Tomlanovich M, Early goal-Directed Therapy Collaborative Group: Early goal-directed therapy in the treatment of severe sepsis and septic shock. N Engl J Med 2001, 345:1368-1377.

2. Rivers EP, Kruse JA, Jacobsen G, Shah K, Loomba M, Otero R, Child EW: The influence of early hemodynamic optimization on biomarker patterns of severe sepsis and septic shock. Crit Care Med 2007, 35:2016-2024.

3. Dellinger RP, Levy MM, Carlet JM, Bion J, Parker MM, Jaeschke R, Reinhart K, Angus DC, Brun-Buisson C, Beale R, Calandra T, Dhainaut JF, Gerlach H, Harvey M, Marini JJ, Marshall J, Ranieri M, Ram- 
say G, Sevransky J, Taylor Thompson B, Townsend S, Vender JS, Zimmerman JL, Vincent JL: Surviving Sepsis Campaign: International guidelines for management of severe sepsis and septic shock: 2008. Crit Care Med 2008, 36:296-327.

4. Parrillo JE: Septic shock \#150; vasopressin, norepinephrine, and urgency. N Engl J Med 2008, 358:954-956.

5. Russell JA, Walley KR, Singer J, Gordon AC, Hébert PC, Cooper DJ, Holmes CL, Mehta S, Granton JT, Storms MM, Cook DJ, Presneill JJ, Ayers D, VASST Investigators: Vasopressin versus norepinephrine infusion in patients with septic shock. N Engl J Med 2008, 358:877-887.

6. O'Brien A, Clapp L, Singer M: Terlipressin for norepinephrineresistant septic shock. Lancet 2002, 359:1209-1210.

7. Morelli A, Rocco M, Conti G, Orecchioni A, De Gaetano A, Cortese G, Coluzzi F, Vernaglione E, Pelaia P, Pietropaoli $P$ : Effects of terlipressin on systemic and regional haemodynamics in catecholamine-treated hyperkinetic septic shock. Intensive Care Med 2004, 30:597-604.

8. Leone M, Albanese J, Delmas A, Chaabane W, Garnier F, Martin C: Terlipressin in catecholamine-resistant septic shock patients. Shock 2004, 22:314-319.

9. Albanese J, Leone M, Delmas A, Martin C: Terlipressin or norepinephrine in hyperdynamic septic shock: a prospective, randomized study. Crit Care Med 2005, 33:1897-1902.

10. Westphal M, Stubbe H, Sielenkamper AW, Borgulya R, Van Aken $\mathrm{H}$, Ball C, Bone HG: Terlipressin dose response in healthy and endotoxemic sheep: impact on cardiopulmonary performance and global oxygen transport. Intensive Care Med 2003, 29:301-308

11. Lange M, Morelli A, Ertmer C, Koehler G, Broking K, Hucklenbruch C, Goering K, Sporkmann M, Lucke M, Bone HG, Van Aken H, Traber DL, Westphal M: Continuous versus bolus infusion of terlipressin in ovine endotoxemia. Shock 2007, 28:623-629.

12. Jolley DH, De Keulenaer BL, Potter A, Stephens DP: Terlipressin infusion in catecholamine-resistant shock. Anaesth Intensive Care 2003, 31:560-564.

13. Morelli A, Ertmer C, Lange M, Westphal M: Continuous terlipressin infusion in patients with septic shock: less may be best, and the earlier the better? Intensive Care Med 2007, 33:1669-1670.

14. Umgelter A, Reindl W, Schmid RM, Huber W: Continuous terlipressin infusion in patients with persistent septic shock and cirrhosis of the liver. Intensive Care Med 2008, 34:390-391.

15. Rehberg S, Ertmer C, Köhler G, Spiegel HU, Morelli A, Lange M, Moll K, Schlack K, Van Aken H, Su F, Vincent JL, Westphal M: Role of arginine vasopressin and terlipressin as first-line vasopressor agents in fulminant ovine septic shock. Intensive Care Med 2009, 35:1 286-1296.

16. Traber D: Selective V1a receptor agonists in experimental septic shock. Crit Care 2007, 11(Suppl 4):P51.

17. Laporte R, Russell J, Landry D, Riviere P: Selective V1a receptor agonist FE 202158 reverses platelet-activating factor-induced hypotension, vascular leak, impaired tissue perfusion, and mortality in rats. Crit Care 2008, 12(Suppl 2):P407.

18. Sakka SG, Reinhart K, Meier-Hellmann A: Prognostic value of the indocyanine green plasma disappearance rate in critically ill patients. Chest 2002, 122:1715-1720.

19. Sakka SG, van Hout N: Relation between indocyanine green (ICG) plasma disappearance rate and ICG blood clearance in critically ill patients. Intensive Care Med 2006, 32:766-769.

20. Creteur J, De Backer D, Vincent JL: Monitoring gastric mucosal carbon dioxide pressure using gas tonometry: in vitro and in vivo validation studies. Anesthesiology 1997, 87:504-510.

21. Groeneveld AB, Kolkman JJ: Splanchnic tonometry: A review of physiology, methodology, and clinical applications. J Crit Care 1994, 9:198-210.

22. Bernadich C, Bandi JC, Melin P, Bosch J: Effects of F-180, a new selective vasoconstrictor peptide, compared with terlipressin and vasopressin on systemic and splanchnic hemodynamics in a rat model of portal hypertension. Hepatology 1998, 27:351-356.

23. Barrett LK, Orie NN, Taylor V, Stidwill RP, Clapp LH, Singer M: Differential effects of vasopressin and norepinephrine on vascular reactivity in a long-term rodent model of sepsis. Crit Care Med 2007, 35:2337-2343.

24. Holmes CL, Walley KR, Chittock DR, Lehman T, Russell JA: The effects of vasopressin on hemodynamics and renal function in severe septic shock: A case series. Intensive Care Med 2001, 27:1416-1421.

25. Luckner G, Mayr VD, Jochberger S, Wenzel V, Ulmer H, Hasibeder WR, Dünser MW: Comparison of two dose regimens of arginine vasopressin in advanced vasodilatory shock. Crit Care Med 2007, 35:2280-2285.

26. Lauzier F, Lévy B, Lamarre $P$, Lesur O: Vasopressin or norepinephrine in early hyperdynamic septic shock: a randomized clinical trial. Intensive Care Med 2006, 32:1782-1789.

27. Dünser MW, Mayr AJ, Ulmer H, Knotzer H, Sumann G, Pajk W, Friesenecker $B$, Hasibeder WR: Arginine vasopressin in advanced vasodilatory shock. A prospective, randomized, controlled study. Circulation 2003, 107:2313-2379.

28. Patel BM, Chittok DR, Russel JA, Walley KR: Beneficial effects of short-term vasopressin infusion during severe septic shock. Anesthesiology 2002, 96:576-582.

29. Morelli A, Ertmer C, Lange M, Dunser M, Rehberg S, Van Aken H, Pietropaoli P, Westphal M: Effects of short-term simultaneous infusion of dobutamine and terlipressin in patients with septic shock: the DOBUPRESS study. $B r$ J Anaesth 2008, 100:494-503.

30. Luckner G, Dünser MW, Jochberger S, Mayr V, Wenzel V, Ulmer H, Schmid S, Knotzer H, Pajk W, Hasibeder W, Mayr A, Friesenecker B: Arginine vasopressin in $\mathbf{3 1 6}$ patients with advanced vasodilatory shock. Crit Care Med 2005, 33:2659-2666.

31. Hamada Y, Karjalainen A, Setchell BA, Millard JE, Bygrave FL: Concomitant stimulation by vasopressin of biliary and perfusate calcium fluxes in the perfused rat liver. Biochem $J 1992$, 281:387-392

32. Ballatori N, Truong AT: Cholestasis, altered junctional permeability, and inverse changes in sinusoidal and biliary glutathione release by vasopressin and epinephrine. Mol Pharmacol 1990, 38:64-71.

33. Holmes CL, Patel BM, Russell JA, Walley KR: Physiology of vasopressin relevant to management of septic shock. Chest 2001 120:989-1002.

34. Edwards RM, Trizna W, Kinter LB: Renal microvascular effects of vasopressin and vasopressin antagonists. $A m$ J Physiol 1989, 256:F274-F278.

35. Grinevich V, Knepper MA, Verbalis J, Reyes I, Aguilera G: Acute endotoxemia in rats induces down-regulation of V2 vasopressin receptors and aquaporin-2 content in the kidney medulla. Kidney Int 2004, 65:54-62.

36. Kiil F: Pressure diuresis and hypertension. Scand J Clin Lab Invest 1975, 35:289-293.

37. Gordon AC, Russell JA, Holmes CL, Singer J, Storms MM, Walley KR: The effect of vasopressin on acute renal failure in septic shock. Am J Respir Crit Care Med 2006, 175(Suppl):A596.

38. Bellomo R, Ronco C, Kellum JA, Mehta RL, Palevsky P, Acute Dialysis Quality Initiative workgroup: Acute renal failure - definition, outcome measures, animal models, fluid therapy and information technology needs: the Second International Consensus Conference of the Acute Dialysis Quality Initiative (ADQI) Group. Crit Care 2004, 8:R204-212.

39. Wun T, Paglieroni T, Lachant NA: Physiologic concentrations of arginine vasopressin activate human platelets in vitro. $\mathrm{Br}$ Haematol 1996, 92:968-972.

40. Dünser MW, Fries DR, Schobersberger W, Ulmer H, Wenzel V, Friesenecker B, Hasibeder WR, Mayr AJ: Does arginine vasopressin influence the coagulation system in advanced vasodilatory shock with severe multiorgan dysfunction syndrome? Anesth Analg 2004, 99:201-206.

41. Russell JA, Walley KR, Gordon AC, Cooper DJ, Hébert PC, Singer J, Holmes CL, Mehta S, Granton JT, Storms MM, Cook DJ, Presneill JJ, Dieter Ayers for the Vasopressin and Septic Shock Trial Investigators: Interaction of vasopressin infusion, corticosteroid treatment, and mortality of septic shock. Crit Care Med 2009, 37:811-818.

42. Annane D: Vasopressin plus corticosteroids: the shock duo! Crit Care Med 2009, 37:1126-1127. 